\title{
Sentidos de política e/de gestão nas pesquisas sobre a escola
}

\author{
Graziela Zambão Abdian' \\ Éderson Andradel \\ Ana Lúcia Garcia Parro'
}

\section{Resumo}

Neste texto, o objetivo é explorar algumas perspectivas teóricometodológicas que se fazem presentes nos estudos sobre/na escola, buscando analisar os sentidos que elas atribuem à política e à gestão. A hipótese é a de que há mudanças teórico-metodológicas nos estudos, no sentido de imprimir a eles a teoria crítica e a necessidade de compreender a escola, no entanto, há, também, continuidades no modo de pensar e fazer pesquisa, as quais apresentam elementos impeditivos de captar e compreender a complexidade do fazer cotidiano da escola. Para contemplar o objetivo, realiza-se análise de três perspectivas teórico-metodológicas sobre o estudo da escola e apresenta-se nova possibilidade para pensar as categorias política e gestão que considere, sobretudo, as políticas de gestão presentes nas escolas públicas brasileiras. 0 desafio é o de compreender o campo da gestão escolar como aquele que produz e (re)produz políticas de gestão, considerando, sobretudo, que na produção de políticas de gestão há um fluxo contínuo de negociações entre os sentidos políticos da ação humana. Finalmente, é indicado que a partir desse pensamento pode ser possível ampliar o campo teóricometodológico da área, sinalizando outras formas de produzir conhecimento que não seja a da gestão escolar como mediadora de uma dada política educacional.

\section{Palavras-chave}

Escola - Política e gestão educacional - Cotidiano.

I- Universidade Estadual Paulista Júlio de Mesquita Neto (Unesp), Marília, SP, Brasil.

Contatos: graziela.maia@gmail.com;

ederson.ufmt@gmail.com;

analucia_caf@hotmail.com 


\title{
Policy and management meanings in the research about schools
}

Graziela Zambão Abdian'

Éderson Andradel

Ana Lúcia Garcia Parro'

\begin{abstract}
The purpose of this article it to explore some theoreticalmethodological perspectives which are found in studies about/in schools, and seeks to analyze the meaning they assign to Policy and Management. Our assumption is that there are theoreticalmethodological changes in the studies whose aim is absorb the critical theory and the need to understand school life; however, there are also continuities in the way research is thought and done which provide elements that prevent them from seizing and comprehending the complexity of what is done in schools in their everyday routine. In order to achieve this purpose, an analysis is conducted in relation to three theoretical-methodological perspectives regarding the study of schools, giving rise to a new way to think the categories of Policy and Management bearing in mind above all the management policies that can be found in Brazilian public schools. The challenge is to see the field of school management as the one which produces and (re) produces management policies, taking into account mainly that, in the production of policies, there is an ongoing flow of negotiations between the political meanings of human action. Finally, we conclude that, based on this way of thinking, it might be possible to expand the theoretical-methodological field of the area, touching other ways of producing knowledge other than the school management as the mediator of a given educational policy.
\end{abstract}

\section{Keywords}

School - Educational policy and management - Everyday routine.

I- Universidade Estadual Paulista Júlio de

Mesquita Neto (Unesp), Marília, SP, Brasil.

Contacts: graziela.maia@gmail.com;

ederson.ufmt@gmail.com;

analucia_caf@hotmail.com 


\section{Introdução}

Neste texto, temos como objetivo principal explorar três perspectivas teóricometodológicas que se fizeram presentes nos estudos sobre/na escola, buscando analisar os sentidos que elas atribuem à política e à gestão. Nossa hipótese é a de que há mudanças teóricometodológicas nos estudos, no sentido de imprimir a eles a teoria crítica e a necessidade de compreender a escola, no entanto, há, também, continuidades no modo de pensar e fazer pesquisa, as quais nos apresentam elementos impeditivos de captar e compreender a complexidade do fazer cotidiano da escola. Pressupomos que, ao explorar as categorias principais de algumas referências que acompanharam as pesquisas na/sobre a escola, teremos elementos para discutir tal hipótese e lançar desafios às nossas novas pesquisas.

Para alcançar nosso objetivo, inicialmente, situamos nossa análise no âmbito das pesquisas que temos realizado para, posteriormente, analisarmos três perspectivas teórico-metodológicas dos estudos sobre/na escola: a proposta marxista de compreensão da escola, a partir de suas faces institucional, organizacional e cultural; a proposta da sociologia das organizações escolares, a qual concebe a escola como organização educativa; a proposta de estudo do/no/com o cotidiano. Finalmente, provocamos o leitor e nos provocamos a pensar as categorias política e gestão de forma diferente daquelas exploradas, a qual considere, sobretudo, as políticas de gestão presentes nas escolas públicas brasileiras (MOUFFE, 2011).

\section{As pesquisas sobre/na escola}

Do ponto de vista teórico, a administração/gestão educacional/escolar se fez de forma binária. Até os anos 1980, apesar de ter existido pensamento contrário (TEIXEIRA, 1968), a base teórica dos estudos foi a teoria administrativa empresarial, representando tal vertente autores clássicos da área (RIBEIRO, 1952; ALONSO, 1976; LOURENÇO FILHO, 2007). No âmbito nacional, a abertura política e o processo de (re)democratização da sociedade e, especificamente, a criação dos programas de pós-graduação em educação permitiram que o referencial crítico fosse incorporado aos estudos de educação e a administração escolar que, de um caráter eminentemente técnico, passa a se constituir, nos escritos acadêmicos, como ato político a serviço da transformação social (ARROYO, 1983; PARO, 1986; FELIX, 1989). A constatação da possibilidade de a administração escolar se constituir como elemento importante para a transformação da sociedade adveio da desconstrução anterior que não diferenciava o processo pedagógico do fabril, portanto, a especificidade do primeiro passa a ser o foco da atenção dos autores que defendem o novo paradigma, subsidiado em abordagem marxista ${ }^{1}$.

A mudança de paradigma da administração empresarial para aquela que considera a especificidade da escola, norteada pela teoria da gestão democrática, rompeu teoricamente com a ideia da semelhança entre as organizações, construiu referencial crítico para a análise da escola, mas conservou o modo de pensar a construção do conhecimento, qual seja a teoria da gestão (agora democrática) que oferece ferramentas suficientes para a transformação da realidade. Esta, por sua vez, não se transforma porque não incorpora tal teoria.

Russo (2004, p. 40), ao dissertar sobre a mudança de paradigma, exemplifica o que estamos argumentando ao dizer, no início de seu texto, que, nos anos 1980, "inverteu-se a ordem determinada pela relação positivista que subordinava as práticas às prescrições da teoria e adotou-se uma posição que se aproxima da relação dialética entre ambas" e, no final de sua análise, indica que quando o “deslocamento produzir um maior peso

1- Destacamos dois autores: Paro (1986), especificamente o capítulo 4, que discute a administração escolar para a transformação social; e Tragtenberg (1985). 
específico para o paradigma de especificidade da escola, certamente passará a influir de maneira mais decisiva na prática que, assim, indicará a tendência de esse paradigma se tornar dominante."

Cabe-nos destacar que a mudança teórica (da teoria da administração empresarial para a teoria crítica marxista) fora acompanhada de uma mudança metodológica. A partir dos anos 1990, conforme indicado por autores da área (MAIA, 2008; RUSSO, 2004; SOUZA, 2006; RUSSO; MAIA, 2009), os pesquisadores se preocupam em estudar a escola e compreendêla a partir das interações com as diretrizes governamentais e com a comunidade intra e extraescolar. Nossos estudos, somados a outros (SOUZA, 2006), puderam constatar que, a partir de então, há predominância, no âmbito da teoria publicada sobre gestão educacional e/ou escolar, do paradigma da especificidade da escola, no entanto, isto não influenciou diretamente a transformação da realidade escolar (RUSSO, 2004).

Do desenvolvimento explicitado, emergiram indagações ao nosso grupo de pesquisa, principalmente relacionadas à transposição direta do paradigma teórico para a realidade escolar e à forma que as pesquisas têm concebido as relações entre teoria e prática. Chamou-nos particular atenção o fato de os autores que romperam com o paradigma empresarial e que construíram o que denominaram teoria crítica da administração/ gestão escolar (via especificidade da escola) darem continuidade a um modelo prescritivo de fazer ciência. Ou seja, é construída uma teoria crítica a partir da especificidade da escola - gestão democrática - para ir à escola dizer que lá ela não existe. Tal constatação também fora realizada por diversos autores da área (SOUZA, 2006; RUSSO; MAIA, 2009; LUCE; MEDEIROS, 2006).

Desde 2005, as pesquisas de nosso grupo se inserem no movimento relatado e têm privilegiado a escola como centro do debate e da produção de conhecimento, no entanto, tem-nos causado conflitos a posição dos referenciais teórico-metodológicos que, apesar de nos proporcionarem a aproximação da escola, não nos ofereceram subsídios para problematizá-la em outras bases, que não aquelas que sobrevalorizam a teoria em detrimento da prática. Neste sentido, realizamos, coletivamente, a busca, o estudo e a análise de obras de autores que pudessem nos aproximar daquilo que denominamos cotidiano escolar.

No início, por termos analisado a história da administração da educação/escolar nas pesquisas e acompanhado o forte intercâmbio com a comunidade acadêmica portuguesa da área, encontramo-nos com a sociologia das organizações escolares, representada, especificamente, por Nóvoa (1995) e Lima (1998). Tais estudos não nos permitiram compreender a categoria em tela - cotidiano -, a qual não é seu foco, nesse sentido, identificamos literatura específica que tratou das amarras históricas da escola, sua face institucional, e pudemos dialogar e fazer conversar os autores. Finalmente e fechando nosso ciclo de estudos, encontramos referencial que, de certa forma, contrapõe-se ao anterior no que tange ao trabalho com o cotidiano e, assim, pudemos tencionar os autores que integraram o percurso acadêmico do grupo.

Em seguida, em cumprimento ao objetivo explicitado na introdução, trazemos os elementos principais de cada um desses referenciais que apresentam elementos para a compreensão da escola e, em seguida, identificamos alguns dos seus limites, parte convergente outra parte divergente entre si, e realizamos proposta de análise para os estudos que têm a escola como foco da produção do conhecimento.

\section{A escola como organização educativa}

No âmbito acadêmico, a construção da escola como organização educativa foi marcada por forte influência da produção portuguesa (NÓVOA, 1995; LIMA, 1998). Esses estudos privilegiam um nível meso de abordagem e identificam que "[...] apesar de conterem visões parcelares da realidade, é evidente que tanto 
as teorias macroscópicas como os estudos microscópicos produziram um conhecimento útil e pertinente do ponto de vista do pensamento e da acção pedagógica." (NÓVOA, 1995, p. 20). Para essas pesquisas

[...] um dos aspectos mais interessantes (e mais críticos) deste movimento é a possibilidade de cruzar a reflexão científica com a inovação educacional, apelando a que os diferentes actores mobilizem criticamente as suas energias, em vez de se refugiarem em teorias defensivas e de justificação. (NÓVOA, 1995, p. 24).

Os pesquisadores centram-se nas organizações escolares, preocupam-se em analisar, explicar, compreender o que elas fazem em seu cotidiano, como constroem o processo educacional.

Barroso (1996) organizou um livro que se constitui de palestras referentes ao simpósio realizado em Portugal em meados dos anos 1990 que abordou especificamente a construção da escola como objeto de estudo. Nesse material, encontramos referências de diversos países europeus que compartilham do que aqui expusemos.

Derouet (1996), por exemplo, diz que há duas razões que contribuíram para a construção do novo objeto de estudo: a evolução endógena da área da administração escolar e a evolução das concepções políticas e administrativas que, integradas, indicam a importância de recomposição da área. A que nos interessa, nesse momento, é a primeira que, segundo Derouet (1996), foi marcada, inicialmente, pelos estudos anglo-saxônicos que abordaram a temática no sentido dos "efeitos de escola", priorizando a questão da eficácia e secundarizando aspectos de fundo como, por exemplo, o modo como as políticas públicas são construídas. Para ele, os estudos que focalizam as organizações escolares como "cidades a construir" marginalizaram a investigação dos primeiros e passaram a abordar a escola como uma cidade política em dois âmbitos: a) local onde se concretizam as políticas educativas; b) local onde se arbitram as exigências contraditórias: adequação entre os princípios e a situação. Esses estudos produziram resultados interessantes no que se refere à diversidade das lógicas de ação que percorrem os estabelecimentos de ensino. Sobre a evolução da área, o autor acrescenta que a investigação, a partir dessa segunda concepção, não deve dar resposta à desordem, mas sim, à coordenação da ação (aos processos - modo de funcionamento). Nesse sentido, aponta o diretor como a principal pessoa para dar andamento ao trabalho, sendo assim, a investigação deve acompanhar os procedimentos que permitem envolver os diversos atores. Derouet (1996) destaca que o funcionamento dos estabelecimentos de ensino é uma questão de justiça (equilíbrio das ideias que norteiam as ações) e de justeza (clareza e acerto entre os recursos e os objetivos). Após abordar a evolução política e administrativa que prioriza, da década de 1990 em diante, a lógica da gestão em detrimento da lógica pedagógica, ele nos convida a evoluir da sociologia da escola para uma ciência mais alargada da administração escolar, "cujo objeto seria a coordenação da acção no seio deste conjunto compósito que, por comodidade, se continua a designar por sistema educativo." (DEROUET, 1996, p. 83).

Lima (1998) propõe um estudo que valorize as formas como os atores se organizam, reproduzindo e produzindo regras. Para ele, a escola é local de reprodução, mas, sobretudo, de produção de políticas, orientações e regras e, assim,

[...] os actores escolares não se limitam ao cumprimento sistemático e integral das regras hierarquicamente estabelecidas por outrem, não jogam apenas um jogo com regras dadas a priori, jogam-no com a capacidade estratégica de aplicarem selectivamente as regras disponíveis $\mathrm{e}$ mesmo de inventarem e construírem novas regras. (LIMA, 1998, p. 94, grifos do autor). 
0 autor enfatiza a necessidade de privilegiar os aspectos referentes às ações dos sujeitos, o que ele chama de "ação organizada" - o cotidiano escolar, em detrimento do "plano de ação para as organizações" - as diretrizes dos órgãos superiores. Conforme o autor, uma oposição à conformidade burocrática pode se concretizar por meio da "infidelidade normativa" e é justamente a prática dela que possibilita à escola ser uma instância "autoorganizada" onde os sujeitos agem e se articulam produzindo regras que atendam aos interesses particulares e também coletivos. Ao opor-se à conformidade normativa (normativismo), a ação organizacional pode promover a infidelidade normativa compreendida, segundo o autor, como "fidelidade dos atores aos seus objetivos, interesses e estratégias" (LIMA, 1998, p. 96).

Essa perspectiva estabelece, como a seguinte, dois planos de ação: o das diretrizes políticas e o da organização escolar e, consequentemente, ao dividirem as tarefas da política e da gestão.

\section{A instituição escolar e seu cotidiano}

Silva Jr. e Ferretti (2004) inauguram nova fase de pesquisa em seus grupos ao focalizarem a instituição escolar como objeto central, com o objetivo de compreender os impactos das reformas educacionais na prática escolar.

Os autores propõem a construção da categoria "prática escolar" a partir de complexa incursão pelos autores Lukács (1981), que trabalha com a prática social considerando a ontologia do ser social, e Heller (1977), que desenvolve a noção de cotidianidade. 0 mais interessante da análise dos autores é que contemplam três faces da escola: a institucional, a organizacional e a cultural e, apesar de atribuírem um elevado grau à densidade histórica da escola, que acaba por imprimir as marcas do Estado liberal (agora neoliberal), defendem que a prática escolar traz em si a potência para a formação do ser social em-si e para-si, ou seja, "quando tal prática resulta no âmbito em-si, trata-se de uma prática alienada e alienante. Quando, ao contrário, torna-se prática orientada pelo para-si, contribui para o desenvolvimento ulterior do ser humano" (SILVA JR.; FERRETTI, 2004, p. 50).

Isto se dá, segundo os autores, porque

0 ordenamento jurídico-burocrático e as políticas produzem as diretrizes para 0 modo de existência da escola na condição dos sistemas e redes escolares, das variadas naturezas escolares atualmente existentes. No entanto, as diretrizes não se reproduzem concretamente tal qual são enunciadas e propostas ou mesmo impostas no plano superestrutural. A organização da esfera educacional e de cada instituição escolar é única, mesmo que ela mantenha relações de identidade com outras instituições da mesma natureza. (SILVA JR; FERRETTI, 2004, p. 58).

Ao trazerem seus autores de base, dialogam com Duarte (2007), cuja preocupação é diferenciar as esferas da vida cotidiana e nãocotidiana. Na primeira, tem-se a reprodução dos indivíduos singulares, a necessidade de sobrevivência ou satisfação das necessidades do homem, características da formação do indivíduo em-si; na segunda, a reprodução adquire um sentido mais amplo, ao agregar necessidades além da individualidade da vida cotidiana, referem-se a atividades que visam à reprodução da sociedade, da realidade produzida historicamente, cuja reprodução está ligada à formação do indivíduo para-si. Nas palavras de Duarte (2007, p. 58):

Uma prática escolar voltada para a formação da individualidade para-si não visa fundamentalmente satisfazer as necessidades já dadas pela vida cotidiana do aluno, mas produzir necessidades de tipo superior, que não surgem espontaneamente, e sim pela apropriação dos conteúdos das esferas de objetivação genérica para-si. 
Sem pretender uma separação rígida entre as esferas cotidianas da reprodução do indivíduo e não cotidianas da reprodução da sociedade, Duarte (2007, p. 57) enfatiza que a educação deve objetivar "a reprodução do educando enquanto indivíduo, mas também visa a atuação desse indivíduo numa prática social, na construção de um determinado tipo de sociedade".

Embora haja convergência de subsídios teóricos entre Duarte (2007) e Silva Jr. e Ferretti (2004), o primeiro realizou prefácio do livro dos segundos, destacando que os autores assumiram o resgate da teoria como desafio interessante no sentido de construir subsídios teóricos para análise empírica das reformas educacionais, mas assumiram o risco da tentativa de apropriação crítica de trabalhos pautados em abordagens distintas dos pressupostos marxistas, deixando-se influenciar pelas perspectivas pós-estruturalista e multiculturalista em sua produção.

De modo geral, Silva Jr. e Ferretti (2004) evidenciam as marcas históricas da face institucional da escola e apontam como sua organização, compreendida por nós como a gestão, dispõe-se para o alcance do objetivo posto historicamente para ela: manutenção do pacto social burguês. No entanto, os autores reconhecem que as diretrizes políticas não se reproduzem tal qual elas são formuladas e, desta forma, indicam a possibilidade de a escola se organizar de forma diferente para o alcance de objetivos emancipatórios. Nesse sentido, podemos dizer que, também nessa abordagem, as diretrizes políticas se fazem fora da escola e a gestão, como organização, é a concretização delas.

\section{O cotidiano como categoria para analisar a escola}

Em busca de novos referenciais, que nos permitissem pensar a escola a partir de elementos ainda não contemplados nas perspectivas anteriores, deparamo-nos com os estudos de curriculistas (ALVES, 2001) que desenvolvem também uma compreensão sobre o cotidiano e os estudos sobre/neles, com base em Certeau (1998).

Para Certeau (1998, p. 41), o cotidiano não é um espaço de reprodução do discurso hegemônico, mas espaço repleto de práticas comuns criativas, descobertas, invenções e muitas possibilidades, lugar sempre passível de transformações, uma história a caminho de nós mesmos, às vezes, velada. As práticas cotidianas do homem comum “[...] constituem as mil práticas pelas quais usuários se reapropriam do espaço organizado pelas técnicas da produção sóciocultural". Isso nos remete a considerar os efeitos das maneiras de fazer dos praticantes do cotidiano como indissociáveis de sua lógica própria.

0 autor evidencia a lógica das práticas cotidianas ao analisar os modos de operação dos usuários e as combinatórias dessas operações que compõem, também, uma cultura. Os usuários, citados pelo autor, representam o homem ordinário, ao qual foi garantida a posição, por muitas vezes ao longo da história e dos estudos sociais, de dominado, supostamente entregue à passividade e à disciplina. Assim, seus modos de operação, objeto de análise do autor, são as maneiras de fazer do homem comum frente às imposições que surgem, de diversas ordens.

Esses modos de operação e as astúcias dos consumidores compõem a rede de uma antidisciplina, que funciona de forma a modificar o que é imposto enquanto é assimilado/consumido, constituindo uma produção secundária, camuflada nos processos de sua utilização, e que subvertem à sua maneira as determinações exteriores. A partir da perspectiva da lógica da prática cotidiana e sobre essas diversas formas, que o homem comum cria, de usar as situações que lhe aparecem, Certeau (1998) desenvolve os conceitos de táticas e estratégias. As primeiras são defınidas como as ações que não podem contar com um lugar próprio, dependem do outro, não são munidas de estratégias e não sustentam uma base pré-determinada de operações, pelo contrário, elas são baseadas na improvisação, representam a arte do fraco, mas são capazes de reagir frente 
a uma necessidade que surja. A tática "tem que utilizar, vigilante, as falhas que as conjunturas particulares vão abrindo na vigilância do poder proprietário. Aí vai caçar. Cria ali surpresas. Consegue estar onde ninguém espera. É astúcia" (CERTEAU, 1998, p. 101).

Enquanto as táticas são determinadas pela ausência de poder, as estratégias são organizadas pelo postulado de um poder, representam ações calculadas e detêm um lugar próprio, significando um espaço de poder hegemônico. A estratégia é a arte do forte e "[...] postula um lugar capaz de ser circunscrito como um próprio e, portanto, capaz de servir de base a uma gestão de suas relações com uma exterioridade distinta" (CERTEAU, 1998, p. 46).

Práticas cotidianas como ler, conversar, cozinhar são consideradas como táticas, artes que não são passivas, pelo contrário, servem de suporte para inúmeras produções, causam pequenas transformações, resultado de bricolagens dos consumidores. Assim, as táticas permeiam o cotidiano do homem ordinário, resultam das habilidades inventivas, aptidões para a criatividade e ocasionam diferentes maneiras de fazer. São pequenas, quase invisíveis, vitórias do herói comum.

Em linhas gerais, Certeau (1998), em sua análise sobre essas práticas cotidianas, apresenta uma perspectiva original em relação aos estudos do cotidiano que enfatizam a passividade dos sujeitos e não se dedicam a analisar os movimentos de criação destes. Dedicando sua obra ao homem ordinário e suas práticas multimilenares, Certeau (1998, p. 93) afirma que este, "Sem sair do lugar onde tem que viver e que lhe impõe uma lei, ele aí instaura pluralidade e criatividade. Por uma arte de intermediação ele tira daí efeitos imprevistos".

Alves (2001) parte dos pressupostos teóricos construídos pelo autor para o desenvolvimento de suas pesquisas nos/dos/ com os cotidianos, especialmente no campo educacional. A autora sistematiza alguns conceitos relacionados ao desenvolvimento das pesquisas e das práticas cotidianas. Alguns dos princípios norteadores são: as maneiras de pensar e pesquisar o cotidiano, as redes coletivas e a produção dos sentidos.

A autora identifica quatro movimentos que possibilitam decifrar a lógica dos cotidianos e os processos necessários para o desenvolvimento dos estudos nos/dos/com os cotidianos. 0 primeiro movimento, denominado pela autora de o sentimento do mundo, define a necessidade do diálogo com outras formas de ver a realidade, que não apenas a dominante, como um mergulho nos cotidianos com o propósito de ir além do que a percepção reconhece. A fim de não mais manter o comum distanciamento entre pesquisador e objeto, mas sim nos atentarmos a todos os detalhes das astúcias e modos de fazer dos praticantes, de modo a reafirmar o cotidiano como espaço/ tempo de saber, criação e grande diversidade.

Nesse sentido, vamos percebendo que só é
possível analisar e começar a entender o
cotidiano escolar em suas lógicas, através
de um grande mergulho na realidade
cotidiana da escola e nunca exercitando
o tal olhar distante e neutro que nos
ensinaram e que aprendemos a usar tão
bem. (ALVES, 2001, p. 15).

O segundo movimento identificado pela autora recebeu o nome de virar de ponta cabeça e propõe um novo modo de olhar para as teorias, conceitos e noções que já conhecemos. Estes precisam ser reconhecidos não apenas como apoio às pesquisas, mas também como seus limites, hipóteses que não representam verdades absolutas e por isso, não necessariamente vão se confirmar. As teorias que sustentamos durante a pesquisa podem tanto guiar nosso caminho quanto limitar nossa percepção quanto à heterogeneidade do cotidiano.

Beber em todas as fontes representa o terceiro movimento e significa a necessidade da ampliação do entendimento que temos de fonte. Os estudos não devem se limitar às produções teóricas do campo, mas também 
incorporar os diversos modos de fazer dos praticantes do cotidiano e os registros destes como fotos, arquivos, memórias, histórias narradas, que devem ser reconhecidos como fontes alternativas para as pesquisas. A partir de diversas fontes é que serão possíveis os estudos nos/dos/com os cotidianos.

0 quarto movimento identificado pela autora, denominado narrar a vida $e$ literaturizar a ciência, indica a necessidade de um novo modo de registrar a pesquisa, outro tipo de escrita que tenha o intuito de comunicar novas preocupações, problemáticas. E que, essencialmente, consiga chegar também aos praticantes dos cotidianos e corrobore a construção e emancipação do conhecimento construído não apenas pelo autor.

Assumimos, junto com a autora, a impossibilidade de uma ou várias teorias possibilitarem uma percepção apurada das práticas cotidianas escolares. Assim, compreendemos a responsabilidade de realizar um mergulho nessa realidade e em nosso objeto de estudo, presenciar as práticas desses atores da educação, buscando formas de problematizá-las e compreendê-las para que, dessa maneira, consigamos entender o que se passa em seu interior e dar conta de responder os empecilhos cotidianos. Quanto a essa forma de desenvolver as pesquisas nos/dos/com os cotidianos, Certeau (1998) nos alerta para as dificuldades inerentes a ela:

Conhecemos mal os tipos de operações em jogo nas práticas ordinárias, seus registros e suas combinações porque nossos instrumentos de análise, de modelização e de formalização foram constituídos para outros objetos e com outros objetivos. 0 essencial do trabalho de análise que deveria ser feito deverá inscrever-se na análise combinatória sutil, de tipos de operações e de registros, que coloca em cena e em ação um fazer-com, aqui e agora, que é um ato singular ligado a uma situação, circunstâncias e atores particulares [...]. Nossas categorias de saber ainda são muito rústicas e nossos modelos de análise por demais elaborados para permitir-nos imaginar a incrivel abundância inventiva das práticas cotidianas. É lastimável constatá-lo: quanto nos falta ainda compreender dos inúmeros artifícios dos 'obscuros heróis' do efêmero, andarilhos da cidade, moradores dos bairros, leitores e sonhadores, pessoas obscuras das cozinhas. Como tudo isso é admirável (CERTEAU, 1998, p. 341-342).

0 autor também critica algumas metodologias utilizadas nas pesquisas que se propõem a analisar as práticas cotidianas e, assim, refere-se a alguns pressupostos necessários para o desenvolvimento dessas pesquisas. Primeiramente, é possível constatar a sua crítica à relação entre o pesquisador e seu objeto, segundo ele, enquanto produz o seu estudo, o pesquisador adota práticas de distância e "neutralização", ele nivela e classifica os dados encontrados e desconsidera descontinuidades e operações heterogêneas.

0 problema existente na adoção de um distanciamento de seu tema por parte do pesquisador, o que é comumente valorizado nas pesquisas cientificas, é que este fica sujeito a não apreensão do objeto de análise como um todo. Em outras palavras, Certeau defende o mesmo pressuposto presente no movimento o sentimento de mundo proposto por Alves (2001) quanto às pesquisas cotidianas da educação. Nessa perspectiva, o autor deve abandonar a prática de distanciamento e se inteirar no cotidiano com todos os sentidos, a fim de compreender o espaço/tempo como parte envolvida nele e, portanto, também passível às táticas e astúcias.

Outro perigo alertado pelo autor quanto às práticas dos pesquisadores é tão comum quanto o primeiro e se refere à perspectiva de que o pesquisador tem a missão de levar o conhecimento sistematizado das práticas cotidianas para os próprios praticantes do cotidiano. Esse modo de olhar pressupõe a 
não apropriação de um saber oficial entre os usuários, apenas de um conhecimento de certa forma "inconsciente", sobre o qual não refletem e que por si só não são capazes de compreender. Trata-se, portanto, de um “[...] saber não sabido [...] um saber sobre os quais os sujeitos não refletem. Dele dão testemunho sem poderem apropriar-se dele. São afınal os locatários e não os proprietários do seu próprio saber-fazer" (CERTEAU, 1998, p. 143).

Assim, os pressupostos defendidos para o desenvolvimento das análises do cotidiano vão ao encontro daqueles explanados por Alves (2001) no campo educacional. Para ambos os autores, os estudos devem ser capazes de identificar as heterogeneidades, a pluralidade de táticas e astúcias e os diversos movimentos de criação presentes nas práticas cotidianas, por meio do diálogo entre várias lógicas de pensamento.

\section{Os sentidos de política e gestão construídos nos estudos sobre/ nas escolas}

Ao redirecionarem o foco da análise do processo de produção das políticas públicas educacionais para o processo de efetivação dessas políticas ou para seus impactos no interior das escolas, os autores trazidos anteriormente buscam diagnosticar as fragilidades dos estudos direcionados à análise do macrocontexto que acabam por desconsiderar os diferentes "graus de aplicação" e os "espaços de manobra" presentes na "tradução das políticas nas práticas” (BALL, 2011, p. 30).

A intenção é avançar em relação às perspectivas que concentram suas análises no macrocontexto, abordagem denominada por Power (2011) de estadocêntrica. Para esses teóricos, segundo a autora, as práticas escolares seriam norteadas por políticas educacionais formuladas nos diferentes âmbitos governamentais, sob influência direta dos organismos internacionais, cujos objetivos são de manutenção das bases que sustentam o modo capitalista de produção. A escola, nessa perspectiva, seria uma instituição reprodutora do sistema social vigente por meio da venda de suas forças de trabalho nos diferentes espaços de produção de bens materiais e não materiais. Os autores destacam, de modo geral, que a realidade, regida por nexos, leis e múltiplas determinações, não é estática e nem intransponível, ao contrário, é constituída por contradições que podem ser compreendidas pelo método materialista histórico.

Os estudos de educação desenvolvidos nesta perspectiva partem da hipótese de que as intervenções do Estado nas instituições públicas são sempre formuladas visando ao atendimento dos interesses de mercado e de conservação da sociedade. 0 objetivo das pesquisas está em analisar os discursos proferidos no âmbito das políticas no sentido "de trazer à luz, a partir de um significativo esforço intelectual, as suas reais intenções. Assim, as análises das políticas públicas educacionais formuladas no âmbito do Estado, embora apresentem algumas especificidades, chegam a conclusões muito próximas" (OLIVEIRA, 2015, p. 24).

Os autores cujas abordagens teóricas foram contempladas anteriormente, de forma diferente, mas não antagônica, indicam que o processo de materialização das políticas públicas educacionais exige que analisemos as diferentes particularidades e as ações dos sujeitos envolvidas em cada contexto. Nosso objetivo é analisar as contribuições e os limites dos sentidos construídos sobre política e gestão nas pesquisas em educação que se propõem estudar a escola com tais perspectivas.

Conforme destacamos, elas apresentam subsídios importantes para o desenvolvimento de pesquisas no campo da gestão escolar, porém, têm nos mostrado algumas fragilidades no tocante aos sentidos referentes às categorias em tela, secundarizando a gestão escolar como meio para os efeitos da política (educacional). A divisão entre política e gestão escolar tem enfraquecido o desenvolvimento teórico metodológico da gestão, pois binariza o campo ao pensar os sentidos das políticas como 
produções governamentais, ora apontado o governo como aquele que não consegue propor uma forma de gestão democrática para a transformação social, ora analisando como a organização escolar e o cotidiano operam com as políticas. Dessa forma, podemos sinalizar uma questão quanto à semelhança dessas perspectivas no que diz respeito aos sentidos atribuídos à gestão escolar como sendo mediadora das políticas educacionais.

Contudo, sinalizamos que as três perspectivas teórico-metodológicas não possuem os mesmos objetivos, as mesmas concepções de mundo, mas reiteramos que ambas pensam a partir da binaridade criada entre política e gestão escolar que, talvez, tenha contribuído para constituir, também, a binaridade teórica no campo da gestão, tratada no inicio do texto.

A perspectiva apresentada por Silva Jr. e Ferretti (2004) analisa a face institucional da escola no sentido de destacar sua contribuição para o pacto social burguês de manutenção do modo de produção capitalista, inclusive, destacando as relações dela com a organização (gestão) e a cultura da escola para tal. Porém, os autores assumem que as diretrizes não se realizam tais quais são formuladas, portanto, a escola pode/deve formar o indivíduo para si, que possa contribuir para a constituição de outra sociedade. Persistem, na análise, os sentidos de política e gestão cindidos.

Os estudos de Nóvoa (1995) e Lima (1998) nos trouxeram um campo profícuo para o desenvolvimento de pesquisas no campo da gestão escolar ao problematizarem o nível meso de análise, bem como o pensamento da escola como organização. Diferente da perspectiva anterior, estes autores nos possibilitam ver a escola como um espaço de negociações, de tensões, dos conflitos, descentralizando a ideia da política como produto pronto e acabado para ser consumido, pois nos apresentam elementos para a compreensão, por exemplo, da infidelidade da escola ao negociar com as políticas governamentais. Contudo, temos que sinalizar mais uma vez que nessa lógica também se pensa a binaridade entre política e gestão ao nos apresentar que tal infidelidade, dentre outros conceitos teórico-metodológicos, é um mecanismo para se (re)organizar a política do governo no contexto meso, ou seja, na escola por sua gestão.

$\mathrm{Na}$ terceira perspectiva teórico-metodológica apresentada, encontramos terreno mais fértil para pensarmos os processos produtivos do cotidiano escolar. Ao nos permitir pensar o cotidiano como espaços/tempos de fazeres criativos em suas múltiplas práticas, Certeau (1998) e Alves (2001) avançam no sentido de indicar que a escola é um lugar de produção e não apenas de reprodução, potencializando a análise das minúcias, das táticas e das estratégias criadas pelos sujeitos. Assim, a pesquisa no campo da gestão escolar a partir dos estudos do cotidiano se torna profícua ao pensar as práticas cotidianas como criação dos sujeitos, permitindo-nos compreender o movimento da política, porém, ainda como um consumir astuto e criativo, separando assim a política da gestão escolar, sendo esta última capaz de movimentar, de múltiplas formas, a política no cotidiano escolar.

Colocamo-nos diante de duas interrogações necessárias para a ampliação dos sentidos teóricometodológicos do campo da gestão escolar no sentido de problematizar a binaridade construída entre política e gestão escolar: como pensar/ analisar as políticas de gestão no cotidiano escolar? Como pensar/analisar as políticas de gestão produzidas pelos governos?

\section{Lançando novos horizontes teórico-metodológicos}

Apontamos uma propositura para refletirmos as questões, que se constitui no que denominamos sentidos de produção articuladas, ou seja, uma e outra não se constituem sozinhas, mas sim em constantes negociações, em constantes lutas por significação do sentido político. As políticas de gestão do governo e da escola são construídas nos sentidos políticos de 
todos os atores sociais envolvidos em qualquer instância (LACLAU, 2011).

Queremos destacar que as políticas não são produtos construídos para serem consumidos em determinado espaço, política não é um texto produzido pelo governo a ser implementado pela escola, ela é marcada por sentidos políticos de formação da própria humanidade.

Nessa perspectiva, não é potente compreender os estudos da gestão como um braço da política, essa visão apresentada nas perspectivas anteriores, resguardando as suas potencialidades e especificidades teóricas, pode fragilizar a gestão escolar ao rechaçar a potencialidade da produção de política pela própria escola.

Diante desse cenário, colocamo-nos com o desafıo de analisar e pensar a produção de política de gestão a partir dos estudos de Chantal Mouffe (2011), trazendo os seus trabalhos acerca dos sentidos políticos e de política na constituição social. Acreditamos que as sinalizações apresentadas por essa autora poderão ser profícuas para o alargamento da compreensão da gestão escolar para além de sua posição de mediadora da política. Tal abordagem pode permitir compreender que existem, no campo da educação, as políticas de gestão produzidas em múltiplos espaços/tempos e que estas estão em constantes negociações umas com as outras.

Neste texto, exploraremos a distinção que Mouffe (2011) estabelece entre "o político" e "a política". A autora considera importante essa distinção, pois pode trazer novos caminhos de se pensar a ação das pessoas no campo de constituição de políticas, uma vez que são múltiplos os espaços/tempos de produção de política, diluindo a ideia de que apenas o governo as produz. Mouffe (2011, p. 16) nos esclarece a questão dizendo:

[...] por "o político" eu entendo a dimensão do antagonismo a qual eu tomo como constitutiva das sociedades humanas, enquanto que por "política" eu significo uma série de práticas e instituições através das quais uma ordem é criada, organizando a coexistência humana no contexto de conflitualidade provido pelo político.

Ao considerar as políticas como proposições constituídas pelos atores sociais, Mouffe (1993) diz que "a política" pode ser entendida como as organizações, instituições, sistematizadas de representatividade, como as igrejas, os sindicatos, os partidos políticos, as escolas. Como uma atividade que cuida da organização da vida das pessoas, não de uma forma distante, mas sim articulada aos processos de construções de identidades coletivas, sem individualismo, marcada pelas negociações e pelas paixões. A compreensão da gestão como política passa a ser vista como uma ação articulada entre vários atores sociais, contudo, emplacada em uma produção sistematizada. Dessa forma, todo e qualquer documento, vídeo, proposta, pronunciamento são produzidos para representar o que se espera acerca das concepções de gestão, dentro da escola e fora dela, há a produção de política de gestão.

Para a produção dessas políticas, Mouffe (1993) articula o sentido de "político", que é inerente a toda e qualquer pessoa, ou seja, uma ação ontológica do conhecimento da própria ação como homem e mulher. É na dimensão "do político" que as relações sociais se formam e são simbolicamente ordenadas, em um terreno de conflitos, em que o antagonismo tem fundamental importância.

Assim, podemos dizer que a política de gestão, assumida pelo sentido político dos atores sociais, transforma-se em uma arena de configuração de múltiplos projetos de gestão escolar, uma esfera de produção de identidades coletivas em torno de uma hegemonização provisória. Podemos compreender assim que a gestão da escola não está dada, pronta e acabada, ou ainda que somente faz novas negociações com as políticas vindas de outras esferas, mas que ela constrói a sua própria política de gestão, assim como qualquer governo, ao 
sinalizar formas de provimento para a direção, por exemplo, também está constituindo uma política de gestão.

Dessa maneira, já podemos nos desafiar e desestabilizar a ideia de que existem políticas públicas que deverão ser mediadas na escola pela gestão escolar, ou seja, questionamos a ideia de que o governo produz uma política para a escola e que ela não condiz com as necessidades críticas de transformação da sociedade pelo processo de emancipação dos sujeitos, bem como aquela, mesmo que potente ao pensar os fazeres escolares na cotidianidade, pensará na política produzida considerando que os sujeitos que nela estão são capazes de negociar possibilidades cotidianas e, em nível meso, uma vez que pelo sentido político ontológico humano, cada espaço/tempo é capaz de produzir as suas próprias políticas.

Pensando na constituição de políticas de gestão, as pesquisas e análises se tornam mais potentes quando assumem o caráter político, pois, como explica a autora, o sentido antagônico permite que múltiplas vozes estejam presentes na constituição de uma política, ou seja, posições distintas em ampla negociação em torno do projeto social que pretende pôr em voga. Isso não significa negar o sentido das políticas do governo, pois entre esses dois sentidos há uma necessária articulação constante, ambos os espaços produzem política de gestão.

A autora ainda potencializa a análise das políticas de gestão ao nos propor o ato de pensar acerca do nível ontológico da ação "do político", bem como do nível ôntico “da política”. 0 nível ôntico se refere à multidão de práticas das políticas constituídas em múltiplos cenários e o ontológico se refere ao modo de se constituir as ações do homem. A política está no nível ôntico porque ela é atrelada a algo existente, a um ente, a uma matéria, a um objeto, por exemplo, as instituições políticas como os sindicatos, é algo que está além do homem, já estabelecido do exterior. 0 político está no nível ontológico, pois se liga à visão de um entendimento do ser enquanto ser, indo além de aparências materiais, preocupa-se com a coisa em si, depende da existência do homem para existir, há no nível ontológico a possibilidade de significação constante, pois o mesmo não é fixo e inacabado, esse nível estabelece arenas de lutas, conflitos, em busca da hegemonização provisória (MOUFFE, 2011).

Por isso, a constituição das políticas, estabelecidas em práticas diversas e em múltiplos lugares preexistentes, as ações dos atores sociais (escolas, sindicatos, igrejas, dentre outras) se articulam e necessitam da propulsão do sentido político de cada pessoa, ou seja, produzimos as políticas em múltiplos espaços, pois somos sujeitos políticos. Toda mudança substancial no nível ôntico, ou seja, no sentido das políticas, irá trazer uma nova concepção do nível ontológico, no sentido político. E o nível ôntico só tem sentido na existência no nível ontológico, pois ele promove a significação das construções sociais. Dessa maneira, pensar o político é dar sentidos às políticas, afastando-se de uma relação produção e implementação.

Pensar a política apenas no nível ôntico é fixá-la, é pensá-la de uma forma imutável, feita por governantes, sem a possibilidade de reconfigurações no cenário escolar, nas práticas pedagógicas. Por isso defendemos tal articulação do nível ontológico, do sentido político, pois nele reside a possibilidade da significação dos múltiplos atores sociais. Ele é o espaço/tempo de conflitos, de lutas, de poder, do antagonismo.

Para Mouffe (2005), o terreno antagônico da constituição de políticas é necessário, uma vez que nos constituímos com e na presença do outro. Porém, a autora salienta que a luta entre inimigos do jogo antagônico pode provocar a destruição do outro, eliminando assim a potencialidade das múltiplas e necessárias negociações existentes no jogo político. Nesse sentido, a autora nos propõe um deslocamento do antagônico para o terreno do agônico, onde no jogo político não há destruição, mas sim uma luta de adversários para a luta pela hegemonização de um dado projeto político. 
As relações antagônicas, ou seja, as lutas contraditórias existentes na sociedade sempre irão existir. $\mathrm{Na}$ produção de políticas de gestão sempre existirão grupos configurados na relação amigo/inimigo, na constituição de identidades coletivas, em um nós e um eles. Os projetos sociais são constituídos nesse jogo de poder, e as políticas de gestão também. Acreditar nessa proposição é aceitar que existem projetos plurais no contexto social.

0 movimento do antagonismo para o agonismo é uma necessidade nesse processo, pois permite pensar a relação amigo/inimigo não com a intencionalidade de destruição mútua, mas sim de acreditar que o outro é um adversário (MOUFFE, 2011). 0 antagonismo é o espaço do contraditório e o agonismo permite uma luta sem destruição do outro. 0 sentido ontológico permite uma leitura do campo político a partir dos conflitos entre adversários.

As três perspectivas teórico-metodológicas apresentadas inicialmente, a nosso ver, têm se colocado em uma lógica antagônica de pensar a produção da política, uma vez que sinalizam que a produção de política se dá no nível governamental, sendo a escola o local de nítida relação de luta contra um inimigo.

Nesse sentido, será potente pensar nas produções de políticas de gestão a partir da presença da categoria adversário, da mudança do antagonismo para o agonismo, pois nos permitem visualizar os embates, as lutas, os conflitos, entre os produtores, entendendo que na produção de políticas múltiplos atores estão envolvidos, sendo elas produzidas em múltiplos cenários. Assumimos essa posição, pois acreditamos que pensar e analisar as políticas de gestão é ir além de uma visão consensual, em que governos produzem e escolas reproduzem ou são infiéis. Assumimos que os embates e discussões não devem ser apagados ou vistos como negativos, mas sim são positivos, pois trazem em seu bojo possibilidades de avanços. Não podemos negar os dissensos, pois podem nos permitir avanços na constituição de políticas, sendo um espaço em que múltiplas vozes podem ser ouvidas.
Mouffe (2011) afirma que é preciso compreender que no terreno político, no campo das políticas, o conflito é um elemento propulsor de um processo democrático, que permite que múltiplos projetos entrem em disputas por hegemonizações provisórias, o que chamamos de conflito consensual. Dessa maneira, no cotidiano escolar e também nos governos há um fluxo contínuo de produção de política de gestão que negociam seus sentidos para efetivação do que acreditam serem as melhores estratégias para uma educação de qualidade. $\mathrm{Ou}$ seja, mesmo quando muitos atores do contexto da prática escolar dizem que as políticas são produtos que vêm de fora, do governo, eles negociam e fazem as suas próprias propostas políticas, e mesmo muitos governantes sinalizando que produzem políticas livre de influência de vários espaços tempos, isso não acontece. Na produção de políticas de gestão há um fluxo contínuo de negociações entre os sentidos políticos da ação humana.

\section{Considerações finais}

Após apresentarmos elementos que constituem três perspectivas teórico-metodológicas presentes nos estudos sobre/na escola, analisamos os sentidos que, respectivamente, elas atribuem à política e à gestão. Indicamos que houve mudanças teórico-metodológicas nos estudos, no sentido de imprimir a eles a teoria crítica e a necessidade de compreender a escola, no entanto, houve, também, continuidades no modo de pensar e fazer pesquisa os quais apresentaram limites para a compreensão do fazer cotidiano da escola. Em nossa análise, pontuamos que estes limites se circunscrevem à concepção de que a política seja feita em âmbito governamental e que a gestão se constitua como as formas de trabalhar a política, recriando-a, reproduzindo-a e/ ou anulando-a.

De forma propositiva, apresentamos o desafio de compreender o cotidiano escolar como aquele que produz e (re)produz políticas de gestão, baseando-nos em categorias 
de Mouffe $(1993$; 2011) sobre a política e o político. Apontamos que o pensamento expresso por esta autora pode permitir a ampliação do campo teórico-metodológico da área, sinalizando outras formas de produzir conhecimento que não seja o da gestão escolar como mediadora de uma dada política educacional.

\section{Referências}

ALONSO, Myrtes. 0 papel do diretor na administração escolar. São Paulo: Difel, 1976.

ALVES, Nilda. Decifrando o pergaminho: 0 cotidiano das escolas nas lógicas das redes cotidianas. In: OLIVEIRA, Inês Barbosa; ALVES, Nilda (Org.). Pesquisa no/do cotidiano das escolas: sobre redes de saberes. Rio de Janeiro: DPA, 2001. p. 13-38.

ARROYO, Miguel. A administração da educação é um problema político. Revista Brasileira de Administração da Educação, Porto Alegre, v. 1, n. 1, p. 122-129, 1983.

BALL, Stephen J. Sociologia das políticas educacionais e pesquisa crítico-social: uma revisão pessoal das políticas educacionais e da pesquisa em política educacional. In: BALL, Stephen J.; MAINARDES, Jefferson (Org.). Políticas educacionais: questões e dilemas. São Paulo: Cortez, 2011. p. 21-53.

BARROSO, João (Org.). 0 estudo da escola. Porto: Porto Editora, 1996.

CERTEAU, Michel de. A invenção do cotidiano: artes de fazer. Petrópolis: Vozes, 1998.

DEROUET, Jean-Louis. 0 funcionamento dos estabelecimentos de ensino em França: um objecto de estudo em redefinição. In: BARROSO, João (Org.) 0 estudo da escola. Lisboa: Porto Editora, 1996. p. 61-85.

DUARTE, Newton. Educação escolar, teoria do cotidiano e a escola de Vigotski. Campinas: Autores Associados, 2007.

FELIX, Maria de Fátima Costa. Administração escolar: problema educativo ou empresarial? São Paulo: Cortez, 1989.

HELLER, Agnes. Sociologia de la vida cotidiana. Barcelona: Península, 1977.

LACLAU, Ernesto. Emancipação e diferença. Rio de Janeiro: EdUerj, 2011.

LIMA, Licínio C. A escola como organização educativa. São Paulo: Cortez, 1998.

LOURENÇO FILHO, Manoel Bergström. Organização e administração escolar: curso básico. Rio de Janeiro: INEP, 2007.

LUCE, Maria Beatriz; MEDEIROS, Isabel Letícia Pedroso de. Gestão democrática da escola pública: práticas e vivências. Porto Alegre: UFRGS, 2006.

LUKÁCS, Georg. Per uma ontologia delles ser sociale. Roma: Riuniti, 1981.

MAIA, Graziela Zambão Abdian. As publicações da ANPAE e a trajetória do conhecimento em administração da educação no Brasil. Revista Brasileira de Política e Administração da Educação, Porto Alegre, v. 24, n. 1, p. 31-50, jan./abr. 2008.

MOUFFE, Chantal. Entorno a Io político. Buenos Aires: FCE, 2011.

MOUFFE, Chantal. 0 regresso do político. Lisboa: Gradiva, 1993.

MOUFFE, Chantal. Por um modelo agonístico de democracia. Revista de Sociologia e Política, Curitiba, n. 25, nov. 2005.

NÓVOA, António. As organizações escolares em análise. Lisboa: Dom Quixote, 1995.

OLIVEIRA, Maria Eliza. Qualidade da educação escolar: discursos, práticas e representações sociais, 2015, 289 f. Tese (Doutorado em Educação) - Faculdade de Filosofia e Ciências da Universidade Estadual Paullista Júlio de Mesquita Neto (UNESP), Marília, 2015. 
PARO, Vitor Henrique. Administração escolar: introdução crítica. São Paulo: Cortez; Campinas: Autores Associados, 1986.

POWER, Sally. 0 detalhe e o macrocontexto: 0 uso da teoria centrada no Estado para explicar práticas e políticas educacionais. In: BALL, Stephen J.; MAINARDES, Jefferson (Org.). Políticas educacionais: questões e dilemas. São Paulo: Cortez, 2011. p. 54-77. RIBEIRO, José Querino. Ensaio de uma teoria da administração escolar. Boletim FFCL/USP, São Paulo, n. 158, 1952.

RUSSO, Daniela Aparecida; MAIA, Graziela Zambão Abdian. A escola como objeto de estudo da ciência da educação no Brasil (19902005). Revista Brasileira de Política e Administração da Educação, Porto Alegre, v. 25, n. 3, p. 523-541, set./dez. 2009.

RUSSO, Miguel Henrique. Escola e paradigmas de gestão. Eccos, São Paulo, v. 6, n. 1, p. 25-42, 2004.

SILVA JÚNIOR, João dos Reis; FERRETTI, Celso João. 0 institucional, a organização e a cultura da escola. São Paulo: Xamã, 2004.

SOUZA, Ângelo Ricardo de. Perfil da gestão escolar no Brasil, 2006. Tese (Doutorado em Educação) - Pontifícia Universidade Católica de São Paulo, São Paulo, 2006.

TEIXEIRA, Anísio. Natureza e função da administração escolar. In: ADMINISTRAÇÃO ESCOLAR: edição comemorativa do I Simpósio Interamericano de Administração Escolar. Salvador: ANPAE, 1968. p. 18-40.

TRAGTENBERG, Maurício. Relações de poder na escola. Educação \& Sociedade, Campinas, v. 7, n. 20, p. 40-45, jan./abr. 1985.

Recebido em: 02.08.2015

Aprovado em: 17.05.2016

Graziela Zambão Abdian é professora doutora assistente do Departamento de Administração e Supervisão Escolar e do Programa de Pós-Graduação em Educação da Faculdade de Filosofia e Ciências de Marília da Universidade Estadual Paulista (Unesp). Líder do Centro de Estudos e Pesquisas em Administração da Educação.

Éderson Andrade é doutorando em educação pela Universidade Estadual Paulista (Unesp). Membro do Grupo de Estudos e Pesquisas em Administração da Educação (Cepae). Pesquisador da Fundação de Amparo à Pesquisa do Estado de Mato Grosso (Fapemat).

Ana Lúcia Garcia Parro é doutora pelo Programa de Pós-Graduação em Educação da Faculdade de Filosofia e Ciências de Marília da Universidade Estadual Paulista (Unesp). Membro do Grupo de Estudos e Pesquisas em Administração da Educação (Cepae). É professora da EMEB Prof. Antonio Rubi Gimenes. 